\title{
Insect-Transmitted Urediniospores of the Rust Puccinia punctiformis Cause Systemic Infections in Established Cirsium arvense Plants
}

\author{
H. Wandeler and S. Bacher
}

Zoological Institute, Community Ecology, University of Bern, Baltzerstr. 6, CH-3012 Bern, Switzerland. Accepted for publication 9 March 2006.

\begin{abstract}
Wandeler, H., and Bacher, S. 2006. Insect-transmitted urediniospores of the rust Puccinia punctiformis cause systemic infections in established Cirsium arvense plants. Phytopathology 96:813-818.

The rust fungus Puccinia punctiformis has potential as a biological control agent for creeping thistle Cirsium arvense, because systemically infected shoots usually die before flowering. The mechanism of rust transfer as well as the spore type responsible for systemic infections have been a source of controversy. One possibility of successful transmission

are able to induce systemic infections in established thistle clones. Furthermore, the weevil origin and the date of rust treatment significantly influenced the number of rust-infected shoots. The earlier a shoot was treated, the higher the probability of rust transmission. These results challenge the current belief that teliospores passing through the soil and infecting root buds are the major cause of systemic infections in the field. Further research on biological control of creeping thistle should therefore concentrate on the application of urediniospores to enhance systemic rust infections.
\end{abstract} is the use of the weevil Ceratapion onopordi as a vector. Our results from a garden experiment show that urediniospores transmitted by the weevil

Puccinia punctiformis (Str.) Röhl is a biotrophic, brachyform rust fungus specific to creeping thistle Cirsium arvense (L.) Scop. Creeping (=Canada) thistle is a noxious weed difficult to control due to its deep-growing perennial root system (7). The rust fungus $P$. punctiformis has long been recognized for its potential for biological control of creeping thistle $(8,9,15,26,30,31)$. However, despite many studies, the life cycle of $P$. punctiformis is still not fully understood (15). This is probably the major reason for the absence of a suitable application technique of this fungus for the biological control of creeping thistle (20). The rust fungus can infect the thistle either locally or systemically (4). Local infections have only a marginal influence on the plant's fitness (22), but systemically infected shoots show large growth disturbances like increased stem length or reduced leaf area (3) and usually die before flowering (31). Local infections are relatively easy to induce by simple application of urediniospores on healthy leaves $(4,21)$. The question of how systemic infections develop in the field, however, has been a source of controversy, but is critical for weed control because only systemic infections kill the plant. Buller and Brown (5) applied urediniospores of $P$. punctiformis on seedlings of creeping thistle and obtained systemically infected plants. Induction of systemic infections in seedlings by urediniospores has been confirmed by multiple researchers $(3,4,24)$. However, seedling infections in the field are likely to be of minor importance since most established thistle patches reproduce clonally (7). It is difficult to obtain systemic infections on shoots of established clones (24) and recent applications of urediniospores on Cirsium arvense shoots of established clones did not result in systemically infected shoots $(18,19,23)$. For effective biological control of creeping thistle, it is imperative to find strategies for obtaining systemic infections of established clones of Cirsium arvense. Van den Ende et al. (28) and French and Lightfield (15) showed in laboratory studies that a treatment of thistle root buds with telio-

Corresponding author: S. Bacher; E-mail address: sven.bacher@zos.unibe.ch

DOI: 10.1094/PHYTO-96-0813

(C) 2006 The American Phytopathological Society
Additional keywords: Apion onopordi, Canada thistle, life cycle, weed.

spores results in systemically infected shoots after planting the root cuttings. These authors hypothesized from their results that teliospores are the major cause of systemic infections in the field. Further studies were done showing that teliospores of $P$. punctiformis seemed to be the most promising spore type to induce systemic infections $(10,12,14,16,27)$. The hypothesized mechanism of the infection process in the field was that teliospores fall to the ground and infect root buds after a passage through the soil. Therefore, the idea came up to promote systemic infections by increasing local infections that produce teliospores in a later stage. Kluth et al. (22) found a positive correlation between the density of urediniosori in August and the number of systemically infected thistle shoots in June of the next year, but there was no effect of urediniospore application on the number of systemically infected shoots. Friedli and Bacher (18) applied urediniospores to thistle shoots resulting in no single systemically infected shoot, despite the formation of local infections. Furthermore, attempts to induce systemic infections by spraying teliospores on soil failed $(11,29)$.

Recently, Friedli and Bacher $(17,18)$ showed in garden experiments with potted plants that a thistle-feeding insect, the weevil Ceratapion (=Apion) onopordi Kirby (Coleoptera: Apionidae), whose larvae develop inside thistle, acts as a vector for the rust fungus and induces systemic infections. Ceratapion onopordi is a small oligophagous weevil that lives on several genera in the subtribe Carduinae $(13,34)$. Females lay their eggs in the shootbase of the plant, and the larvae feed inside the shoots above- and below-ground and pupate in the root collar (6). Weevil and rust engage in a mutualistic interaction, each profiting from the presence of the other $(1,18)$. While weevils spread the plant pathogen, they benefit from a higher adult weight when developing in rustinfected shoots. Friedli and Bacher $(17,18)$ hypothesized that females of the weevil transmit spores of the rust to healthy plants during oviposition. Once in the stem, the mycelium is thought to enter the root system where it overwinters and infects root buds. In the following spring, systemically infected shoots emerge from such a root system. As all weevils used in the experiments described above $(17,18)$ were field-collected at a site where also the rust fungus occurred, no conclusions could be drawn about the 
spore types responsible for the infection. Urediniospores are likely to be the spore type because the weevils had been treated with urediniospores prior to the experiments. However, since nothing was known about spore contamination of the weevils in the field, teliospores from the field may also have been responsible for the rust transfer.

For effective use of $P$. punctiformis as a biocontrol agent, it is crucial to know which spore type future research should concentrate on. This knowledge will also improve our understanding of the life cycle of $P$. punctiformis. Using field-collected weevils from two different sites, one with and one without rust infection, we investigated in a garden experiment whether urediniospores transmitted by the weevil Ceratapion onopordi induce systemic infections in thistle shoots. In particular, the hypothesis was that weevils treated with urediniospores induce more systemic infections than untreated weevils. Furthermore, the effect of the weevil origin and the infestation date on the success of systemic infection was tested. The timing of spore transfer seems to be important as Friedli and Bacher discussed (18). The mycelium of the rust has to reach the root system before the shoot dies in autumn and therefore an earlier weevil infestation would increase the probability of rust infection.

\section{MATERIALS AND METHODS}

Plant, weevil, and rust collections. In April 2003, roots of Cirsium arvense were collected from a rust-free population near Bern, Switzerland. Root pieces of 10 to $13 \mathrm{~cm}$ length were planted at a depth of 10 to $12 \mathrm{~cm}$ in the center of plastic pots (16liter soil volume) filled with organic, loamy soil. Adults of Ceratapion onopordi were collected in the field at one site from Cirsium arvense plants that were partly rust-infected and at another site from the related species Cirsium vulgare, which is not a host to $P$. punctiformis. At the second site and its surrounding area (radius of $500 \mathrm{~m}$ ), no Cirsium arvense plants and consequently no rust were present. Thus, Ceratapion onopordi adults from the Cirsium vulgare site were not contaminated with $P$. punctiformis from the field. Weevils were kept singly for at least 14 days on healthy Cirsium arvense leaves that were consecutively harvested from a rust-free thistle population in Bern. Only egg-laying females were used for the experiment. Likewise, urediniospores of $P$. punctiformis and urediniospore-bearing leaves were repeatedly collected from systemically infected plants at the thistle population near Bern. The spores and leaves were stored at $4^{\circ} \mathrm{C}$ for up to 2 weeks until use. After urediniospores had been stored at $4^{\circ} \mathrm{C}$ for 2 weeks, about $50 \%$ of them germinated within $24 \mathrm{~h}$ in a drop of water on an object slide in the laboratory.

Experimental setup and data collection. The experiment was conducted from May 2003 to June 2004 in the garden of the Zoological Institute, University of Bern, Switzerland. We had four experimental treatments consisting of weevils from one of the two collection sites, either with or without urediniospores, as well as a general control $(N=20$ pots each). In a first step, the first emerged shoot of each experimental pot was treated when it reached a minimum height of $5 \mathrm{~cm}$. The treatments were implemented as follows: (treatment 1) single females of Ceratapion onopordi collected on Cirsium arvense were fed for $24 \mathrm{~h}$ with urediniosporebearing leaves, and afterwards, they were powdered with urediniospores using a fine brush (in the order of magnitude of about 1,000 spores per weevil) and immediately confined for $72 \mathrm{~h}$ to the Cirsium arvense shoot in the pot by means of a transparent plastic cylinder (10.5-cm-diameter, height depending on the shoot length) sealed on top with gauze mesh; (treatment 2) as treatment 1 , except weevils were fed healthy leaves instead of urediniospore-bearing leaves and were not powdered with urediniospores (direct control to treatment 1); and (treatments 3 and 4) correspond to treatments 1 and 2, respectively, but single females of Ceratapion onopordi collected from Cirsium vulgare were used.
In the general control, only a transparent plastic cylinder was put over the thistle shoot to measure the natural rust-infection rate in the garden. After $72 \mathrm{~h}$, weevils and cylinders were removed.

The 100 pots were divided into four temporal blocks (=cohorts) of 25 pots each, because the first shoots emerged poorly synchronized, and at the beginning of the experiment, there were not 80 egg-laying weevils available. Within these four blocks, each five pots were randomly assigned to one of the four experimental treatments and to the general control. The first emerged shoot of each pot was treated beginning 13 May 2003 (first block), 24 May 2003 (second block), 4 June 2003 (third block), and 30 June 2003 (fourth block). The pots from all temporal blocks were placed in a completely randomized setup in the Zoological Institute garden. All shoots that emerged until early August were treated with the same treatment applied to the first shoot in the pot before, using the same weevil female. After this date, the weevils stopped laying eggs, and later emerged shoots were free from weevils. Because some weevils died during the experiment, they were replaced by another weevil from the same treatment. Pots were watered and hand-weeded if necessary.

The total number of healthy and systemically infected shoots in each pot was cumulatively counted from August to October 2003 and from April to June 2004.

Spore type. Several spore samples from an additional sampling were investigated to get information about the composition concerning spore types. From April to June 2004, urediniospore samples of $P$. punctiformis were collected from urediniosori of 10 to 20 randomly chosen, systemically infected shoots at two different sites and stored at $-20^{\circ} \mathrm{C}$. Four samples $(11,18$, and 26 May and 6 June) were collected from a site near Bern (the same site where urediniospores for the experiment described above were collected; area: $112 \mathrm{~m}^{2}, 14.6$ shoots per $\mathrm{m}^{2}, 4.1 \%$ systemically rust-infected shoots) and two samples (25 April and 28 May) derived from a site in the Swiss Valais (area: $2,128 \mathrm{~m}^{2}, 12$ shoots per $\mathrm{m}^{2}, 12 \%$ systemically rust-infected shoots). Of each sample, 1,000 spores were checked under a microscope for the presence of teliospores, which are easily distinguishable from urediniospores.

Statistical analyses. Differences in the total number of shoots between the treatments were tested with a one-way analysis of variance (ANOVA) (SPSS 12.0, SPSS Inc., Chicago, IL) and post-hoc Tukey tests for each census date separately. Differences in the number of shoots per pot in 2003 and 2004 were compared with a paired $t$ test (SPSS 12.0). The count data were square roottransformed to meet assumptions of normality and homogeneity of variances.

At the first census date in October 2003, systemically rustinfected shoots had already emerged, but only in very small numbers and only in treatment 3 (weevils from Cirsium vulgare with urediniospores). Thus, the difference in the incidence of systemic infections between treatments 3 and 4 (equal to treatment 3 but without urediniospores) in autumn 2003 was analyzed with exact binary logistic regression with the treatment as factor and the temporal block as weight variable (LogXact 6, Cytel Software Corporation, Cambridge, MA). A Poisson regression was performed to test for effects of the factors weevil origin (Cirsium arvense site or Cirsium vulgare site), rust treatment (with or without urediniospores), and temporal block (date of the treatment of the first shoot) on the number of rust-infected plants per pot (LogXact 6) in 2004. The temporal block was treated as a category, whereas a dummy variable was created comparing pots of the temporal blocks two to four to pots of the first block using a contrast. The influence of the number of treated shoots on the incidence of rust (yes/no) in a pot was analyzed separately for each single treatment with an exact binary logistic regression (LogXact 6).

In treatment 2, the first shoot of one pot was mistakenly treated with urediniospores, whereas in two other pots, all thistles died in summer 2003 due to mildew infection. These three pots were 


\begin{tabular}{|c|c|c|c|c|c|}
\hline \multirow{3}{*}{$\begin{array}{l}\text { No. of systemically } \\
\text { infected shoots per pot }\end{array}$} & \multicolumn{5}{|c|}{ Total number of pots (pots per block 1/2/3/4) } \\
\hline & \multicolumn{2}{|c|}{ Weevil origin Cirsium arvense } & \multicolumn{2}{|c|}{ Weevil origin Cirsium vulgare } & \multirow[b]{2}{*}{ General control } \\
\hline & With rust & Without rust & With rust & Without rust & \\
\hline \multicolumn{6}{|l|}{2003} \\
\hline 1 & $0 \quad(0 / 0 / 0 / 0)$ & $0 \quad(0 / 0 / 0 / 0)$ & $4(3 / 1 / 0 / 0)$ & $0 \quad(0 / 0 / 0 / 0)$ & $0 \quad(0 / 0 / 0 / 0)$ \\
\hline 0 & $20(5 / 5 / 5 / 5)$ & $17(4 / 5 / 5 / 3)$ & $16(2 / 4 / 5 / 5)$ & $20(5 / 5 / 5 / 5)$ & $20(5 / 5 / 5 / 5)$ \\
\hline \multicolumn{6}{|l|}{2004} \\
\hline 8 & - & - & - & - & $1(0 / 0 / 1 / 0)$ \\
\hline 7 & - & - & $1(0 / 1 / 0 / 0)$ & - & - \\
\hline 6 & - & - & $1 \quad(1 / 0 / 0 / 0)$ & - & - \\
\hline 5 & - & - & - & $1(0 / 0 / 0 / 1)$ & - \\
\hline 4 & $1(1 / 0 / 0 / 0)$ & - & $3(2 / 0 / 0 / 1)$ & - & - \\
\hline 3 & $1(1 / 0 / 0 / 0)$ & - & $2(1 / 0 / 1 / 0)$ & $1(1 / 0 / 0 / 0)$ & $2(0 / 1 / 1 / 0)$ \\
\hline 2 & $2(0 / 2 / 0 / 0)$ & $1(0 / 0 / 1 / 0)$ & $1(0 / 1 / 0 / 0)$ & - & $2(0 / 1 / 0 / 1)$ \\
\hline 1 & $3(1 / 0 / 1 / 1)$ & $5(2 / 1 / 1 / 1)$ & $3(0 / 0 / 1 / 2)$ & $5(2 / 1 / 2 / 0)$ & $5(2 / 1 / 0 / 2)$ \\
\hline 0 & $13(2 / 3 / 4 / 4)$ & $11(2 / 4 / 3 / 2)$ & $9(1 / 3 / 3 / 2)$ & $13(2 / 4 / 3 / 4)$ & $10(3 / 2 / 3 / 2)$ \\
\hline
\end{tabular}

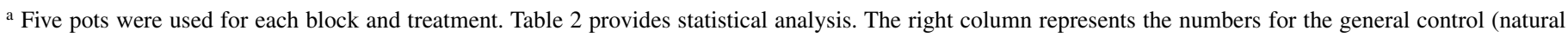
rust infection level in the garden).

TABLE 2. Results of a Poisson regression with the number of Cirsium arvense shoots systemically infected by Puccinia punctiformis per pot as the dependent variable and the three factors rust, weevil, and temporal block as independent variables ${ }^{\mathrm{a}}$

\begin{tabular}{lccc}
\hline Parameter estimates & Beta $^{\mathrm{b}}$ & $\mathrm{SE}^{\mathrm{c}}$ & $P$ value \\
\hline Constant & -0.508 & 0.322 & 0.114 \\
Rust vs. no rust & 0.862 & 0.265 & 0.002 \\
Weevil Cirsium vulgare vs. & & & \\
$\quad$ weevil Cirsium arvense & 0.796 & 0.261 & 0.002 \\
Block 2 vs. block 1 & -0.776 & 0.313 & 0.013 \\
Block 3 vs. block 1 & -1.182 & 0.362 & 0.001 \\
Block 4 vs. block 1 & -0.882 & 0.329 & 0.007 \\
$\quad$ Deviance (123.4) (71 df) & & & $<0.001$ \\
\hline
\end{tabular}

a The reference level for the temporal block variable was block 1 . The weevil Ceratapion onopordi was collected from either the host plant Cirsium arvense or Cirsium vulgare, and half of the weevils were powdered with urediniospores of $P$. punctiformis.

b Point estimate of the $\beta$ coefficient.

c Standard error of the $\beta$ coefficient.

therefore excluded from all analyses, resulting in an unbalanced design. Means are given \pm standard error throughout the text.

\section{RESULTS}

Experimental rust transfer. The total number of thistle shoots in 2003 and 2004 ranged from 1 to 20 shoots and from 2 to 16 shoots per pot, respectively. The mean value was $6.8 \pm 0.4$ shoots in 2003 and $7.0 \pm 0.3$ shoots per pot in 2004 . There was no significant difference between the treatments (ANOVA: year 2003: $F_{4,92}=0.505, P=0.732$; year 2004: $\left.F_{4,92}=0.562, P=0.691\right)$ and between the years (paired $t$ test: $t_{96}=-1.628, P=0.107$ ) in the number of shoots per pot.

Local infections developed in a few pots belonging to all treatments in summer 2003, indicating that not only urediniospores from the treatment were responsible for them, but also urediniospores from external sources. In the months from August until October 2003, systemically infected shoots emerged in $20 \%$ of the pots that had been treated with weevils collected from Cirsium vulgare and urediniospores of $P$. punctiformis (treatment 3). All infected shoots were side shoots from the first emerged ones, whereas three of those had been treated within the first and one in the second temporal block (Table 1, 2003). The comparison of this treatment to its control (treatment 4; weevils collected from Cirsium vulgare, without urediniospores) resulted in a weak significant difference (exact binary logistic regression: $\mathrm{df}=1, P$-mid $=$ 0.028), indicating an effect of weevil-transmitted urediniospores on the occurrence of systemic rust infections.

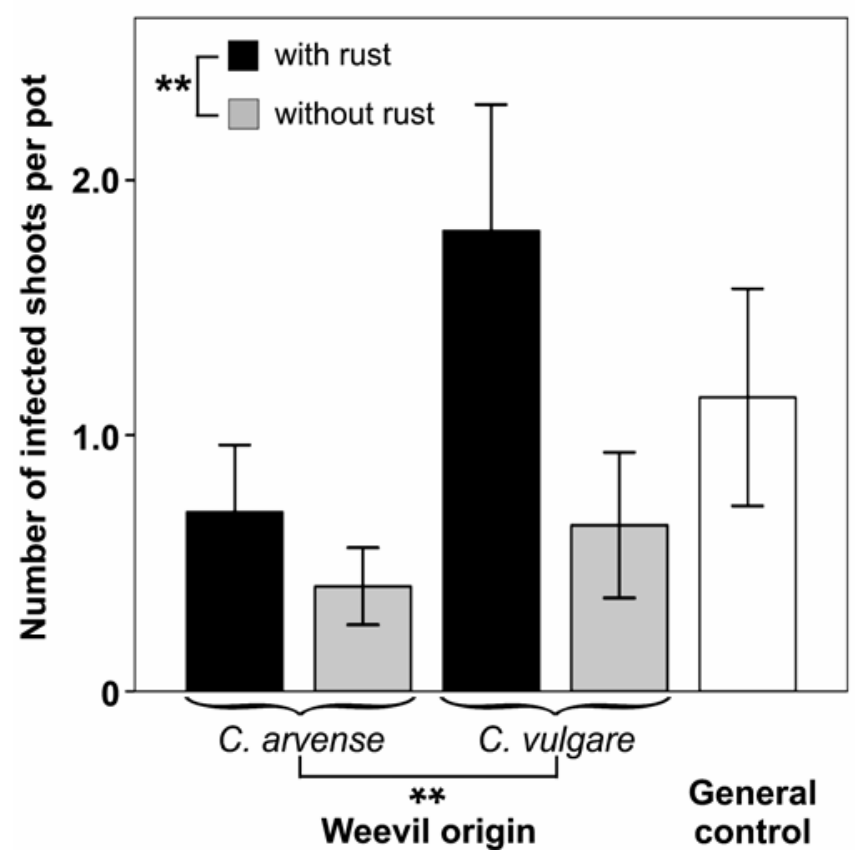

Fig. 1. Effect of the different treatments in the year 2003 on the number of Cirsium arvense shoots systemically infected by Puccinia punctiformis in the pots emerged until June 2004. The treatment with urediniospores as well as the origin of the weevil Ceratapion onopordi significantly influenced the number of rust-infected shoots per pot. The white bar represents the general control (garden level). Table 1 (2004) and Table 2 provide detailed numbers and statistics. Bars show means and one standard error. **, $P<0.01$.

In spring 2004, systemically infected shoots emerged in $42 \%$ of the pots (Table 1, 2004). The factor rust treatment significantly influenced the number of rust-infected shoots per pot (Table 2; Fig. 1). The mean number of rust-infected shoots in the pots treated with weevils powdered with urediniospores was 2.4 times higher than the number of rust-infected shoots in the pots treated with weevils only. The number of rust-infected shoots per pot was also significantly influenced by the factor weevil origin. The pots treated with weevils from Cirsium vulgare showed a 2.2 times higher mean number of rust-infected shoots compared with pots treated with weevils from Cirsium arvense (Table 2; Fig. 1). Likewise, the date of the treatment of the first shoot (temporal block) significantly influenced the number of rustinfected shoots. In the pots treated within the first block, significantly more rust-infected shoots grew compared with pots of other blocks (Table 2; Fig. 2). The proportion of infected shoots 
per pot ranged between $9.0 \pm 5.1 \%$ (treatment 4 ) and $21.5 \pm 5.9 \%$ (treatment 3). The number of rust-infected shoots per pot in the general control was very high $(1.15 \pm 0.42$; systemically infected shoots emerged in $50 \%$ of the pots), resulting from the established local population of Ceratapion onopordi in the Zoological Institute's garden.

To test whether the infected shoots were induced by the treatments, the number of pots with infected shoots was related to the number of shoots treated per pot. We expected that the more shoots treated in a pot, the higher the probability for rust incidence in this pot. In treatments 1 and 3 only (weevils with urediniospores), the number of shoots treated in each pot had a significant influence on the number of pots with rust-infected shoots (Table 3 ), indicating that the rust-infected shoots in the treatments 1 and 3 resulted from our treatment with urediniospores.

Spore type. The frequency of occurrence of teliospores was different at the two collection sites. In contrast to the site in the Swiss Valais where $5 \%$ of the total spores were teliospores in April 2004 and increased slightly to 6\% in May, no teliospores were found at the site near Bern until June, with the exception of $1 \%$ teliospores in the second sample in May (18 May 2004). Production of teliospores seems to be highly site dependent, as also found by French and Lightfield (15).

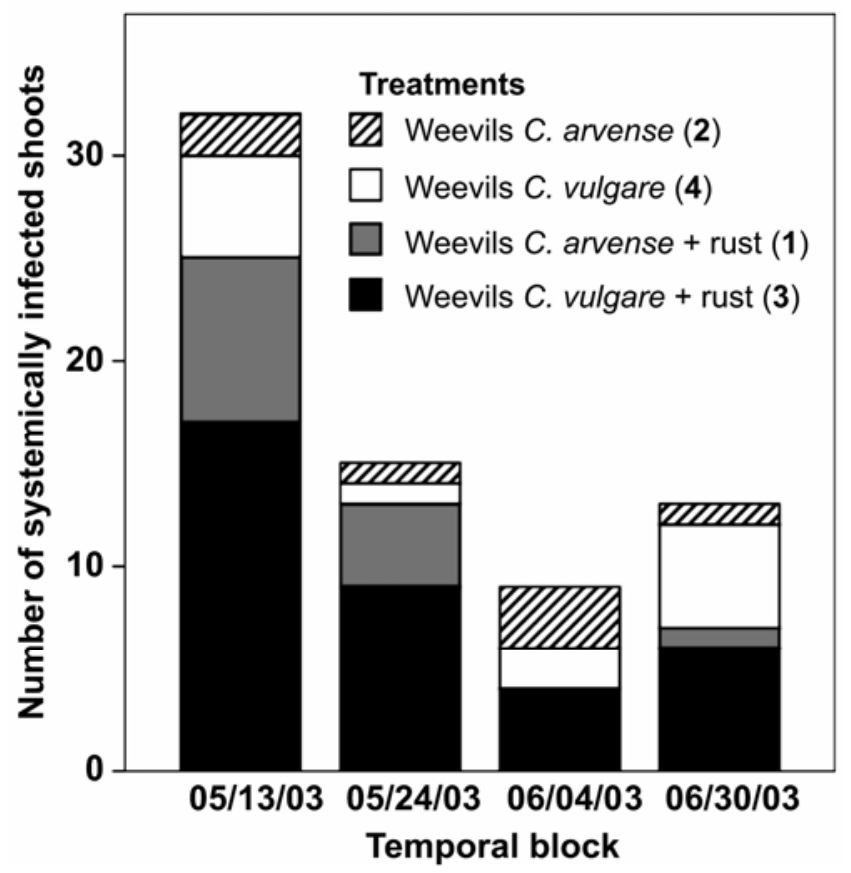

Fig. 2. Number of Cirsium arvense shoots systemically infected by Puccinia punctiformis in pots treated within the four temporal blocks. The treatment in the first temporal block $(05 / 13 / 03)$ caused the highest number of systemically infected shoots. Table 2 provides detailed statistics.

\section{DISCUSSION}

The present study clearly shows that urediniospores can cause systemic infections in established thistle clones when transmitted by the vector Ceratapion onopordi. It further shows that several conditions can modulate the effectiveness of rust transmission. In particular, rust incidence depends on the date of treatment and the weevil origin or its original food plant. Pots treated early had more rust-infected shoots than pots treated later. Thus, it is important to treat the plants early in the year to get a high infection success. One reason for that could be that the mycelium needs a specific number of warm days to reach the root system before winter. Systemically infected shoots were observed in the same year in which the treatment was applied, but only in pots treated within the first and second temporal block, also indicating the mycelium growth rate as a limiting factor. This finding corresponds to the results of a seedling infection experiment from Menzies (24), who also found infected shoots appearing later in the same year in seedlings inoculated early in the season with urediniospores. In seedlings inoculated at a later date, the first infections appeared the following spring. In seedlings, the mycelium from urediniospores germinating on leaves is able to reach the root system on its own, whereas in established plants or plants grown from root pieces, this is not possible because of the greater distance from leaves to the roots (18). However, after transmission by the vector Ceratapion onopordi, the distance to reach the root system is much shorter as the urediniospores already are in the lower part of the stem. Additionally, Menzies (24) found that farther down in the stem, the mycelium grows faster when it moves into the inner cortex and phloem. A vector may therefore be necessary to transmit the urediniospores successfully to shoots of an established clone.

A second reason for higher infection success at earlier dates could be related to the weevil's limited oviposition period (2), as in all probability, the rust is transmitted during oviposition $(18 ; \mathrm{H}$. Wandeler and S. Bacher, unpublished PCR data). The weevil Ceratapion onopordi starts laying eggs in April. After reaching its peak oviposition rate, egg production starts to decrease after about 1 month and stays low until August (personal observation). Therefore, it is likely that most females used during the first temporal block (13 May) laid eggs, while in later blocks the egg laying rate was probably lower. However, if the weevils did not oviposit during the $72 \mathrm{~h}$ they were confined to the experimental shoots, no urediniospores would have been transmitted.

The influence of the weevil origin might have to do with a different oviposition potential of the weevils; weevils from Cirsium vulgare are in general larger than weevils from Cirsium arvense and larger females lay more eggs $(2,18)$. The larger egg laying potential may in turn increase the probability of oviposition during the 3 days the weevils had been confined to the thistles and therefore the probability of successful rust transfer. Unfortunately, it was not possible to examine the stems for eggs without the risk of disturbing the experiment. A further reason that may be brought up for higher rust transmission by larger weevils is that more

TABLE 3. Influence of the number of Cirsium arvense shoots treated on the likelihood of pots to contain shoots systemically infected by Puccinia punctiformis, analyzed by exact binary logistic regression

\begin{tabular}{|c|c|c|c|c|c|c|c|c|c|}
\hline \multirow[b]{2}{*}{ Treatment } & \multicolumn{3}{|c|}{ Summary statistics (likelihood ratio) } & \multicolumn{3}{|c|}{ Parameter estimates (constant) } & \multicolumn{3}{|c|}{ Parameter estimates (shoots treated) } \\
\hline & Value & $\mathrm{df}$ & $P$ value & Beta $^{a}$ & $\mathrm{SE}^{\mathrm{b}}$ & $P$ value & Beta $^{a}$ & $\mathrm{SE}^{\mathrm{b}}$ & $P$ value ${ }^{c}$ \\
\hline 1 & 14.31 & 2 & 0.001 & -1.928 & 0.606 & 0.002 & 0.256 & 0.127 & 0.048 \\
\hline 2 & 5.04 & 2 & 0.081 & -0.254 & 0.544 & 0.640 & -0.106 & 0.121 & NS \\
\hline 3 & 6.31 & 2 & 0.043 & -1.084 & 0.578 & 0.061 & 0.691 & 0.321 & 0.022 \\
\hline 4 & 8.27 & 2 & 0.017 & -0.922 & 0.506 & 0.069 & 0.037 & 0.201 & NS \\
\hline 5 & 3.53 & 2 & 0.172 & -0.671 & 0.507 & 0.185 & 0.232 & 0.135 & NS \\
\hline
\end{tabular}

a Point estimate of the $\beta$ coefficient.

b Standard error of the $\beta$ coefficient.

c NS $=P>0.05$. 
urediniospores were attached to larger individuals. However, after powdering, the number of spores was high anyway and thus unlikely to be a limiting factor. In the first rust transmission experiments with the weevil as a vector (17), systemically infected shoots emerged in numbers comparable to the experiment reported here, although the weevils had not been powdered.

The spore samples for the first temporal block were collected at the beginning of May at the site in Bern. It is very unlikely that these samples contained teliospores because the formation of urediniosori at rust-infected thistles started only at the end of April at this site (personal observation) and teliosori are mainly formed later in the season under short-day conditions $(4,32)$. The probability of teliospores being present in the experimental samples increased in the collections used in later temporal blocks; however, the main effect of the rust treatment was visible in the first block. The site with $6 \%$ teliospores of the total spores in May was located in the Swiss Valais (southern Switzerland), where the climate is much warmer and thus the vegetation well advanced compared with the site in Bern. The proportions of teliospores to occur in samples used in the experiment in the later temporal blocks would have been small (about 1\%, in accordance with the spore type results) and the germination rate of teliospores without using stimulators is known to be negligible $(27,28)$, particularly for teliospores collected early in the season (27). During powdering, about 1,000 spores were attached to the weevil, but this number will soon have decreased due to the weevil's activity. Therefore, we judge the probability as having been marginal that teliospores were responsible for weevil-transmitted systemic rust infections in our experiments.

In 2004, the number of pots with systemically infected shoots was related to the number of treated shoots only in treatments 1 and 3 (weevils and urediniospores). This result strongly supports the success of the experimental infection. Nevertheless, a relatively high mean number of infected shoots per pot was found in the general control without any weevils and urediniospores. As we have been conducting experiments using both organisms for a few years, there exists an established garden population of the weevil and the rust. These weevils from the garden population are likely to have infested some of the experimental plants and to have transmitted urediniospores, resulting in systemically infected shoots. The plants of the general control might be most susceptible to the stray weevils from the garden, as these shoots were not infested by experimental weevils. Shoots from the other treatments already contained eggs and Ceratapion onopordi seems to avoid laying additional eggs in previously infested, healthy shoots $(1,17)$. Thus, the number of systemically infected shoots in the treatments 1 to 4 should not be strongly influenced by the garden population. Therewith, the low rust incidence in the treatments 2 and 4 can be explained. We cannot exclude that also teliospore infection via root buds was partly responsible for the systemic infections, but the infection pattern argued for infections caused by the weevil-transmitted urediniospore treatments. On the one hand, systemically infected shoots already emerged in the autumn 2003 , but only in pots from one urediniospore treatment. On the other hand, the higher rust incidence in the first temporal block can only be explained by the treatments. An effect of teliospores deriving from local infections would have similarly appeared in all treatments, because local infections, as a potential source for teliospores, were distributed over all treatments. The observed variability in infection rates could have been reduced by conducting the experiment under more controlled conditions. In this study, the general control indicated a high background infection level, resulting from the garden population of the weevil. However, a clear infection pattern was still found, although the background noise increased the variability in the data points. Our setup allows drawing conclusions on infection processes in natural situations in contrast to results from artificial, but better controlled laboratory experiments.
Van den Ende et al. (28) conducted germination and inoculation experiments with teliospores directly applied to roots and concluded that teliospores are the origin of systemic infections in Cirsium arvense by $P$. punctiformis. In their study, the proportion of successfully infected root segments was 55 to $77 \%$. French and Lightfield (15) found an infestation rate of $52 \%$ for root buds inoculated with stimulated teliospores. In a third study, the percentage of root buds infected depended on the Cirsium arvense clone, ranging from 34 to $43 \%$ (12). However, direct application of teliospores on root segments and digging the root segments in the soil afterward is far from the natural infection process because teliospores that fall on the ground would have to pass through the soil to attach to the creeping thistle root system. To our knowledge, no studies have shown systemic infections caused by $P$. punctiformis teliospores applied to the soil of either potted or naturally grown thistles $(11,29)$. In our experiment, $21 \pm 6 \%$ of all shoots in treatment 3 (weevil from Cirsium vulgare and urediniospores) were systemically infected. In the field, weevils naturally come into contact with urediniospores by walking on rustinfected plants, to which the weevils are highly attracted (25). Under seminatural conditions, neither direct application of urediniospores on thistles nor spraying teliospores on the ground resulted in systemic rust infections $(11,18,23,29)$. However, weevil-transmitted urediniospores repeatedly induced systemic infections, in the present as well as in previous garden experiments $(17,18)$ and also in a field study $(\mathrm{H}$. Wandeler and S. Bacher, unpublished data). Therefore, we propose that insect-transmitted urediniospores play a major role in the induction of systemic rust infections in the field.

Our study clearly shows that urediniospores can cause systemic infections of the creeping thistle. If they are transferred by the weevil Ceratapion onopordi, urediniospores can lead to systemic infections in plants with an established root system, not only in seedlings. Further, we showed that the success of infection depends on the weevil origin. Other factors may influence infection, for example the specific thistle clone (12) and the rust line used (33). The use of urediniospores for biological control has great practical advantages over the use of teliospores. In contrast to teliospores, urediniospores germinate readily and can be produced in large amounts from continuously induced local infections.

\section{ACKNOWLEDGMENTS}

We thank C. Germann for helping to find the weevil sites; K. Ruchti for her help with the experiment and her valuable comments on earlier versions of this manuscript; and K. Lüdi, L. L. Kinkel, and two anonymous reviewers for comments that improved the manuscript. We gratefully acknowledge financial support of the Swiss NSF through the NCCR 'Plant Survival'. The study was funded by the Swiss Agency for the Environment, Forests and Landscape (BUWAL) and the Swiss Federal Office for Agriculture (BLW).

\section{LITERATURE CITED}

1. Bacher, S., and Friedli, J. 2002. Dynamics of a mutualism in a multispecies context. Proc. R. Soc. Lond. 269:1517-1522.

2. Bacher, S., Friedli, J., and Schär, I. 2002. Developing in diseased host plants increases survival and fecundity in a stem-boring weevil. Entomol. Exp. Appl. 103:191-195.

3. Bailiss, K. W., and Wilson, I. M. 1967. Growth hormones and the creeping thistle rust. Ann. Bot. 31:195-211.

4. Buller, A. H. R. 1950. Researches on Fungi. Vol. III. Toronto University Press, Toronto.

5. Buller, A. H. R., and Brown, A. M. 1941. Urediniospores as the origin of systemic mycelia in Puccinia suaveolens. Phytopathology 31:4.

6. Dieckmann, L. 1977. Beiträge zur Insektenfauna der DDR: ColeopteraCurculionidae (Apioninae). Pages 7-143 in: Beiträge zur Entomologie. Vol 27. Akademie-Verlag, Berlin.

7. Donald, W. W. 1994. The biology of Canada thistle (Cirsium arvense). Rev. Weed Sci. 6:77-101.

8. Ferdinandsen, C. 1923. Biologiske Undersøgelser over Tidselrust (Puccinia suaveolens (Pers.) Rostr.). Nord. Jordbrugsforsk. 5-8:475-487. 
9. Frantzen, J. 1994. An epidemiological study of Puccinia punctiformis (Str.) Röhl as a stepping-stone to the biological control of Cirsium arvense (L.) Scop. New Phytol. 127:147-154.

10. Frantzen, J. 1994. The effect of temperature on the germination of teliospores of Puccinia punctiformis. Phytopathology 84:1043-1046.

11. Frantzen, J., and Scheepens, P. C. 1993. Biologische bestrijding van akkerdistel met de roestschimmel Puccinia punctiformis. Nederlands Ministerie van Landbouw, Natuurbeheer en Visserij. CABO-DLO Report 184.

12. Frantzen, J., and Van der Zwerde, W. 1994. Quantitative resistance of Cirsium arvense to root bud infection by Puccinia punctiformis. Biocontrol Sci. Technol. 4:223-228.

13. Freese, G. 1995. The insect complexes associated with the stems of seven thistle species. Entomol. Gen. 19:191-207.

14. French, R. C. 1990. Stimulation of germination of teliospores of Puccinia punctiformis by nonyl, decyl, and dodecyl isothiocyanates and related volatile compounds. J. Agric. Food Chem. 38:1604-1607.

15. French, R. C., and Lightfield, A. R. 1990. Induction of systemic infection in Canada thistle (Cirsium arvense) by teliospores of Puccinia punctiformis. Phytopathology 80:872-877.

16. French, R. C., Nester, S. E., and Binder, R. G. 1994. Volatiles from germinating Canada thistle seed and root cuttings that stimulate germination of teliospores of the Canada thistle rust fungus, Puccinia punctiformis. J. Agric. Food Chem. 42:2937-2941.

17. Friedli, J., and Bacher, S. 2001. Direct and indirect effects of a shoot-base boring weevil and plant competition on the performance of creeping thistle, Cirsium arvense. Biol. Control 22:219-226.

18. Friedli, J., and Bacher, S. 2001. Mutualistic interaction between a weevil and a rust fungus, two parasites of the weed Cirsium arvense. Oecologia 129:571-576.

19. Guske, S., Schulz, B., and Boyle, C. 2004. Biocontrol options for Cirsium arvense with indigenous fungal pathogens. Weed Res. 44:107-116.

20. Julien, M. H., and Griffiths, M. W. 1999. Biological Control of Weeds: A World Catalogue of Agents and Their Target Weeds. 4th ed. CAB International, Wallingford, UK.

21. Kluth, S., Kruess, A., and Tscharntke, T. 2001. Interactions between the rust fungus Puccinia punctiformis and ectophagous and endophagous insects on creeping thistle. J. Appl. Ecol. 38:548-556.

22. Kluth, S., Kruess, A., and Tscharntke, T. 2003. Influence of mechanical cutting and pathogen application on the performance and nutrient storage of Cirsium arvense. J. Appl. Ecol. 40:334-343.

23. Kluth, S., Kruess, A., and Tscharntke, T. 2005. Effects of two pathogens on the performance of Cirsium arvense in a successional fallow. Weed Res. 45:261-269.

24. Menzies, B. P. 1953. Studies on the systemic fungus, Puccinia suaveolens. Ann. Bot. 17:551-569.

25. Moravie, M.-A., Borer, M., and Bacher, S. 2006. Neighbourhood of host plants influences oviposition decisions of a stem-boring weevil. Basic Appl. Ecol. (In press.)

26. Thomas, R. F., Tworkoski, T. J., French, R. C., and Leather, G. R. 1994. Puccinia punctiformis affects growth and reproduction of Canada thistle. Weed Technol. 8:488-493.

27. Turner, S. K., Kwiatkowski, A., Fay, P. K., and Sands, D. C. 1986. Factors affecting germination of teliospores of Puccinia obtegens. Plant Dis. 70:390-391.

28. Van den Ende, G., Frantzen, J., and Timmers, T. 1987. Teleutospores as origin of systemic infection of Cirsium arvense by Puccinia punctiformis. Neth. J. Plant Pathol. 93:233-239.

29. Van Leest, A. S., and Scheepens, P. C. 1994. Effectiveness of the rust fungus Puccinia punctiformis as a possible biological control agent against Canada thistle (Cirsium arvense). Rapport-DLO Instiuut voor Agrobiologisch en Bodemvruchtbaar-heidsonderzoek zoek 25:1-19.

30. Völker, K., and Boyle, C. 1994. Bean rust as a model system to evaluate efficiency of teliospores induction, especially in the potential mycoherbicide Puccinia punctiformis. Weed Res. 34:275-281.

31. Watson, A. K., and Keogh, W. J. 1980. Mortality of Canada thistle due to Puccinia punctiformis. Pages 325-332 in: Proc. 5th Int. Symp. on Biological Control of Weeds. E. S. Delfosse, ed. Commonwealth Scientific and Industrial Research Organisation, Melbourne.

32. Wilson, M., and Henderson, D. M. 1966. British Rust Fungi. Cambridge University Press, London, UK.

33. Wyss, G. S., and Müller-Schärer, H. 1999. Infection process and resistance in the weed pathosystem Senecio vulgaris-Puccinia lagenophorae and implications for biological control. Can. J. Bot. 77:361-369.

34. Zwölfer, H. 1965. A list of phytophagous insects attacking wild Cynareae species in Europe. Pages 31-34 in: Report XV. Commonwealth Institute of Biological Control, European Station, Delémont. 